\title{
Inappropriate usage of intravenous proton pump inhibitors and associated factors in a high complexity hospital in Brazil
}

\author{
Laura M BISCHOFF'1, Laura S M FARAC0 ${ }^{1}$, LuCas V MACHAD0 ${ }^{1}$, Alex V S BIALECKI'1, \\ Gabriel M de ALMEIDA ${ }^{1}$ and Smile C C BECKER ${ }^{1,2}$
}

Received: 6 July 2020

Accepted: 15 September 2020

\begin{abstract}
Background - Intravenous (IV) use of proton pump inhibitors (PPIs) is advised only in cases of suspected upper gastrointestinal bleeding (UGIB) or impossibility of receiving oral medication, although there has been a persistent practice of their inappropriate use in health institutions. Objective - The purpose of our study was to measure the inappropriate use of IV PPIs in a high complexity hospital in Brazil and to estimate its costs. Methods - Retrospective study of 333 patients who received IV omeprazole between July and December of 2018 in a high complexity hospital in Brazil. Results - IV omeprazole was found to be appropriately prescribed in only $23.4 \%$ patient reports. This medication was administered mainly in cases of suspected UGIB (19.1\%) and stress ulcer prophylaxis in patients with high risk of UGIB unable to receive medication orally (18.7\%). It was observed a statistically significant association between adequate prescription and stress ulcer prophylaxis in patients with high risk of UGIB unable to receive medication orally; patient nil per os with valid indication for PPIs usage; prescription by intensive care unit doctors; prescription by emergency room doctors; intensive care unit admission; evolution to death; sepsis; and traumatic brain injury $(P<0.05)$. On the other hand, inadequate prescription had a statistically significant association with surgical ward prescription and non-evolution to death $(P<0.05)$. The estimated cost of the vials prescribed inadequately was US\$1696. Conclusion - There was a high number of inappropriate IV omeprazole prescriptions in the studied hospital, entailing greater costs to the institution and unnecessary risks.
\end{abstract}

HEADINGS - Proton pump inhibitors. Peptic ulcer. Gastrointestinal hemorrhage. Inappropriate prescribing. Off-label use. Endoscopy. Medical overuse.

\section{INTRODUCTION}

The most efficient medications for gastric acid suppression nowadays are proton pump inhibitors (PPIs), available in the Market since 1989 with the launch of omeprazole ${ }^{(1)}$. These pharmaceutical drugs inhibit $\mathrm{H}+, \mathrm{K}+$-ATPase of gastric parietal cells, causing an increase in stomach $\mathrm{pH}^{(2)}$.

The main clinical indications approved by the Food and Drug Administration for the administration of this class of medication are treatment for erosive esophagitis and its maintenance; treatment of gastro esophageal reflux; reduction of risk of gastric ulcer associated to non-steroid anti-inflammatory drug (NSAID); Helicobacter pylori eradication; hyper secretive pathological conditions, such as Zollinger-Ellison syndrome; and duodenal ulcer treatment and its maintenance ${ }^{(3)}$.

However, the intravenous (IV) preparations, according to recent studies, are reserved for cases of patients with: gastric hyper secretion associated with neoplastic conditions and Zollinger-Ellison unable to receive medication orally; severe cases of non-variceal upper gastrointestinal bleeding (UGIB); gastrointestinal hemorrhage with risk of recurrent continuous bleeding; and in stress peptic ulcer prophylaxis in high risk patients on the intensive care unit (ICU) without access to enteral feeding or unable to receive orally, nil per os (NPO $)^{(4,5)}$. According to the Brazilian National Health
Surveillance Agency (ANVISA), intravenous sodium omeprazole is indicated when the usage of the pharmaceutical form of pills is not possible. Sodium omeprazole is to be used to treat: gastric or duodenal peptic ulcer; reflux esophagitis; Zollinger-Ellison syndrome; and prophylaxis for aspiration of gastric content during general anesthesia in high risk patients ${ }^{(6)}$.

The adequate use of IV PPIs in patients with suspected nonvariceal UGIB, according to current international guidelines, consists on the implementation of an initial bolus of $80 \mathrm{mg}$ and, subsequently, an infusion of $8 \mathrm{mg} / \mathrm{h}$ for 72 hours, executing a new treatment for 72 hours if recurrence of bleeding ${ }^{(7,8)}$. However, in a systematic review and meta-analysis conducted by Sachar, Vaidya and Laine, it was observed that the utilization of PPIs intermittently, with an initial bolus of $80 \mathrm{mg}$ followed by $40 \mathrm{mg}$ every 12 hours presented similar outcomes to the continuous infusion of $8 \mathrm{mg} / \mathrm{h}^{(9)}$. In patients unable to receive oral drugs, the IV dosage should be individualized in accordance to the specific indication ${ }^{(10,11)}$.

The inappropriate use of IV PPIs has been observed in various studies, especially in cases without the suspicion of $\mathrm{UGIB}^{(4,11-14)}$. There are, however, studies demonstrating that oral preparations of PPIs have similar efficacy to IV preparations in cases of bleeding ulcers suggesting that it seems to be no need for such an excessive IV administration in hospitals resulting undoubtedly to higher institutional costs ${ }^{(15-17)}$.

Declared conflict of interest of all authors: none

Disclosure of funding: no funding received

${ }^{1}$ Universidade do Extremo Sul Catarinense, Departamento de Medicina, Criciúma, SC, Brasil. ${ }^{2}$ Hospital São José, Criciúma, SC, Brasil.

Corresponding author: Laura Bischoff. E-mail: lauramarconbischoff@gmail.com 
There is little data regarding the usage of IV PPIs in Brazil and Latin America. This present study had, therefore, the objective of evaluating the indications, posologies, duration of treatment and cost of IV omeprazole prescriptions, the only IV PPI available in the studied institution.

\section{METHODS}

This present study was approved by the Ethics and Research with Human Beings Committee from the Universidade do Extremo Sul Catarinense (3.084.465) and from the Hospital São José Criciúma (3.145.505).

This study was held in a high complexity hospital in the Southern region of the state of Santa Catarina, Brazil, estimating that in six months about a thousand patients receive IV omeprazole in this institution and the minimum sample calculation was of 291 patient records. Three hundred thirty three patient records of patients who received IV omeprazole were assessed retrospectively in the period of July to December of 2018. Patients with age inferior to 18 years were excluded.

An instrument for data collection was used, evaluating sex, age, race and comorbities of the patient; which was the indication for initiating treatment with IV omeprazole; what were the reasons for its use when there was no suspected UGIB; if the patient was subjected to upper digestive endoscopic exam (UDE) or surgical procedure in case of suspected upper gastrointestinal bleeding and reasons for non-subjection of the patient; UDE findings, if performed; surgical procedure findings, if performed; IV omeprazole's posology; duration of treatment; service responsible for prescribing the medication; admission in the intensive care unit during hospital stay; prescription by emergency room doctor; if there was evolution to death during hospital stay; if there was IV omeprazole suspension in 48 hours when initiated by inadequate reason; total number of vials of this pharmaceutical drug utilized during hospital stay; number of vials utilized inadequately; cost involved with the use of this medication; if the indication of use was adequate; if the dosage was adequate; if the duration of treatment was adequate and if the prescription of IV omeprazole was entirely correct.

The indications considered as adequate for the administration of this IV drug were upper gastrointestinal bleeding or its suspicion before a confirmatory procedure, like endoscopy or surgery; stress ulcer prophylaxis in patients with high risk of upper gastrointestinal bleeding and unable to receive medication orally; and patient in NPO with valid indication for oral PPI. Of the patients with suspected non-variceal UGIB, were considered with appropriate indication those presenting peptic ulcer disease with stigmata of high risk of rebleeding in the endoscopic or surgical report according to Forrest classification: Forrest IA (spurting hemorrhage), IB (oozing hemorrhage), IIA (visible vessel) or IIB (adherent clot), in addition to erosive disease of the esophagogastric mucous membrane with active bleeding, tumoral lesion with active bleeding, or while awaiting for confirmatory procedure. If the patients did not match the formerly cited situations, it was also considered an adequate indication those patients who had the medication suspended in up to $48 \mathrm{~h}$ after the result of the endoscopy. Of the patients unable to receive enteral diet, those in NPO or intolerant to oral medication with valid indication for PPIs were considered with adequate indication, or those that were receiving prophylaxis for stress ulcer because of high risk of upper gastrointestinal bleeding.
For stress ulcer prophylaxis, we considered as critically ill patients with high risk for upper gastrointestinal bleeding those with at least one of the following criteria: hemorrhagic diathesis - platelet count $<50.000$ by $\mathrm{mm}^{3}$, an International Normalized Ratio (INR) $>1.5$ or an activated partial thromboplastin time (aPTT) $>2$ the control value; mechanical ventilation $>48$ hours; history of gastrointestinal ulcer or gastrointestinal bleeding in the last year; traumatic brain injury; traumatic spinal cord injury; burn; or at least two of the following findings: sepsis; period of intensive care unit stay superior to one week; gastroinstestinal bleeding for six or more days; glucocorticoid therapy (superior to $250 \mathrm{mg}$ of hydrocortisone or equivalent); or use of NSAID or antiplatelet agents ${ }^{(5)}$.

Posology was considered adequate when, in the case the patient had UGIB suspicion, a bolus of $80 \mathrm{mg}$ followed by continuous infusion of $8 \mathrm{mg} / \mathrm{h}$ for 72 hours or bolus of $80 \mathrm{mg}$ followed by 40 $\mathrm{mg}$ every 12 hours for 72 hours was instituted. If the usage was due to stress ulcer prophylaxis in patients with high risk of UGIB unable to receive it orally or in patients in NPO with valid indication for oral PPI, it was considered adequate the use of $40 \mathrm{mg}$ of intravenous omeprazole once a day.

Regarding the duration of treatment, all the patients who did not present any indication for intravenous omeprazole use and those with UGIB suspicion who did not suspend the medication in up to 48 hours after the absence of valid indication or absence of stigmata of peptic ulcer with high risk of rebleeding in the diagnostic procedure results were considered inadequate.

In cases where the indication was considered inadequate, dosage and duration of treatment were also considered inadequate. Only when indication, dosage and duration of treatment were adequate, the prescription was considered entirely adequate.

The collected data was analyzed with the help of the software IBM Statistical Package for the Social Sciences (SPSS) version 21.0. The quantitative variables were expressed by median and interquartile amplitude or minimum and maximum value when these did not present normal distribution and by mean and standard deviation when these did present with normal distribution. Qualitative variables were expressed by frequency and percentage.

For the calculation of the number of inadequately prescribed vials and the cost of these to the hospital, we multiplied the number of days of inadequate prescription by the number of vials used in the period. The hospital onus was calculated by multiplying the total number of inadequate vials by the cost of each vial in the time of the study.

The statistical tests were made with a significance level $\alpha=$ 0.05 and, therefore, $95 \%$ confidence interval. The data distribution in relation to normality was evaluated by application of the Kolmogorov-Smirnov test. The investigation of association between qualitative variables was made by application of the Pearson's chisquare test, Fisher's exact test and the likelihood ratio test, followed by residual analysis when statistical significance was observed.

\section{RESULTS}

Of the 333 patients analyzed, 13 were excluded due to age inferior to 18 years, with a subsequent sample of 320 patients. The studied population was composed mainly by men $(54.4 \%)$, whites $(93.4 \%)$ with a mean age of approximately 60 years $( \pm 16.29)$. The comorbities most commonly found in these patients are described in TABLE 1. 
TABLE 1. Demographic data and comorbities of patients using intravenous omeprazole.

\begin{tabular}{lc}
\hline & $\begin{array}{c}\text { Mean } \pm \text { SD, } \mathbf{n}(\%) \\
\mathbf{n}=320\end{array}$ \\
\hline Age (years) & $59.92 \pm 16.29$ \\
Sex & \\
Male & $174(54.4)$ \\
Female & $146(45.6)$ \\
& \\
Race & \\
White & $298(93.4)$ \\
Black & $11(3.4)$ \\
Brown & $9(2.8)$ \\
Indigenous & $1(0.3)$ \\
Not specified & 1 \\
Comorbities & \\
Systemic arterial hypertension & \\
Pneumonia & $125(39.1)$ \\
Diabetes Mellitus & $81(25.3)$ \\
Malignant neoplasia & $76(23.8)$ \\
Acute coronary syndrome & $62(19.4)$ \\
Sepsis & $45(14.1)$ \\
Cerebrovascular accident & $44(13.8)$ \\
COPD & $28(8.8)$ \\
Congestive heart failure & $20(6.3)$ \\
Chronic hepatopathy & $15(4.7)$ \\
Traumatic brain injury & $15(4.7)$ \\
UTI & $12(3.8)$ \\
Gallstones & $10(3.1)$ \\
Other & $9(2.8)$ \\
\hline & $9(2.8)$ \\
stonic kidney disease & $95(29.7)$ \\
\hline
\end{tabular}

SD: standard deviation; COPD: chronic obstructive pulmonar disease; UTI: urinary tract infection.

The suspicion of presence of UGIB was the most frequent indication for initiating the use of IV omeprazole, occurring in $19.1 \%$ of the cases. The median of duration of treatment was of 4.00 days, with an interquartile amplitude of 2.00-8.00, and periods of duration varying from 1 to 61 days were found (TABLE 2).

The largest part of the prescriptions was made by doctors of the ICU $(39.7 \%)$ and the prescription was initiated by emergency room doctors in only $10.3 \%$ of the cases. Half of the patients were admitted to the ICU during hospital stay and $69(21.6 \%)$ patients evolved to death (TABLE 3).

Regarding the group of patients with UGIB suspicion, $34.4 \%$ did not undergo any procedure for confirmation of presence of upper gastrointestinal bleeding. The endoscopic report of patients who did undergo UDE showed normal or unspecific findings in most cases $(31.6 \%)$. Regarding the $28(73.6 \%)$ patients who did not have confirmed high risk of bleeding, $9(32.2 \%)$ remained utilizing the IV omeprazole for more than 48 hours after receiving the UDE report (TABLE 4).

The indication for use of IV omeprazole was considered adequate in only $41.6 \%$ of cases. Regarding posology, the following findings were observed in reference to the group with UGIB suspicion: 15 (24.6\%) in use of initial bolus of $80 \mathrm{mg}$ followed by
TABLE 2. Indications for initiating intravenous omeprazole usage and duration of treatment.

\begin{tabular}{|c|c|}
\hline & $\begin{array}{c}\mathrm{n}(\%), \text { Median } \\
(\text { minimum }- \text { maximum) } \\
\mathrm{n}=320\end{array}$ \\
\hline \multicolumn{2}{|l|}{ Adequate indications } \\
\hline $\begin{array}{l}\text { Upper gastrointestinal bleeding } \\
\text { suspicion }\end{array}$ & $61(19.1)$ \\
\hline $\begin{array}{l}\text { Stress ulcer prophylaxis in patient with } \\
\text { high risk of UGIB unable to receive } \\
\text { orally }\end{array}$ & $60(18.7)$ \\
\hline $\begin{array}{l}\text { Patient in NPO with valid PPI } \\
\text { indication }\end{array}$ & $12(3.7)$ \\
\hline \multicolumn{2}{|l|}{ Inadequate indications } \\
\hline $\begin{array}{l}\text { PUD prophylaxis after surgical } \\
\text { procedure }\end{array}$ & $58(18.1)$ \\
\hline $\begin{array}{l}\text { Stress ulcer prophylaxis in patients with } \\
\text { low risk of UGIB }\end{array}$ & $40(12.5)$ \\
\hline Abdominal pain & $23(7.2)$ \\
\hline Absence of clear indication & $19(5.9)$ \\
\hline $\begin{array}{l}\text { Stress ulcer prophylaxis and high } \\
\text { risk of UGIB with possibility of oral } \\
\text { administration }\end{array}$ & $12(3.7)$ \\
\hline $\begin{array}{l}\text { Anticoagulants/platelet antiaggregant/ } \\
\text { anti-inflammatories usage }\end{array}$ & $11(3.4)$ \\
\hline $\begin{array}{l}\text { Abdominal pain associated with } \\
\text { vomiting }\end{array}$ & $8(2.5)$ \\
\hline Other & $16(5.0)$ \\
\hline Duration of treatment (days) & $4.00(1-61)$ \\
\hline
\end{tabular}

UGIB: upper gastrointestinal bleeding; PUD: peptic ulcer disease; NPO: nil per os; PPI: proton pump inhibitor.

TABLE 3. Sectors involved in prescribing intravenous omeprazole and evolution to death.

\begin{tabular}{|c|c|}
\hline & $\begin{array}{c}\mathrm{n}(\%) \\
\mathrm{n}=320\end{array}$ \\
\hline \multicolumn{2}{|l|}{ Prescribing sector } \\
\hline ICU & $127(39.7)$ \\
\hline General medicine & $81(25.3)$ \\
\hline Surgery & $56(17.5)$ \\
\hline Oncology & $18(5.6)$ \\
\hline Gastroenterology & $16(5.0)$ \\
\hline Cardiology & $8(2.5)$ \\
\hline Pneumology & $5(1.6)$ \\
\hline Other & $9(2.8)$ \\
\hline \multicolumn{2}{|c|}{ Prescription by ER doctor } \\
\hline Yes & $33(10.3)$ \\
\hline No & $287(89.7)$ \\
\hline \multicolumn{2}{|c|}{ Admission in the ICU during hospital stay } \\
\hline Yes & $160(50.0)$ \\
\hline No & $160(50.0)$ \\
\hline \multicolumn{2}{|l|}{ Evolution to death } \\
\hline Yes & $69(21.6)$ \\
\hline No & $251(78.4)$ \\
\hline
\end{tabular}

ICU: intensive care unit; ER: emergency room. 
TABLE 4. Performance of procedures for confirmation of bleeding in patients using intravenous omeprazole with suspicion of upper gastrointestinal bleeding.

\begin{tabular}{lc}
\hline & $\mathbf{n}(\%)$ \\
$\mathbf{n}=61$
\end{tabular}

Reason for not performing any procedure $(n=21)$

Critically ill patient

$6(28.6)$

Recent UDE

Unnecessary UDE or patient too well for procedure

$4(19.0)$

$4(19.0)$

Not informed

$7(33.4)$

UDE results $(\mathrm{n}=38)$

Normal or unspecific findings

$12(31.6)$

Peptic ulcer disease with stigmata of low risk of rebleeding (Forrest IIC or III)

$10(26.3)$

Peptic ulcer disease with stigmata of high risk of rebleeding (Forrest IA, IB, IIA or IIB)

$8(21.1)$

Gastro-esophageal varicose veins

Esophagogastric mucous membrane erosive disease

without active bleeding

Esophagogastric mucous membrane erosive disease with active bleeding

Tumoral lesion with active bleeding

Gastric angiodysplasia without signs of recent bleeding

Medication suspended in up to $48 \mathrm{~h}$ in case of absence of indication for maintenance of intravenous omeprazole $(n=28)$

Yes

$19(67.8)$

No

$9(32.2)$

UDE: upper digestive endoscopy.

$40 \mathrm{mg}$ every 12 hours and $8(13.1 \%)$ in use of bolus of $80 \mathrm{mg}$ on IV omeprazole followed by continuous infusion of $8 \mathrm{mg} / \mathrm{h}$ for 72 hours. In regard to the group of patients with stress ulcer prophylaxis and high risk of gastrointestinal bleeding unable to receive medication orally or in NPO with valid indications for PPI usage, $70(97.2 \%)$ used $40 \mathrm{mg}$ of IV omeprazole once a day. In any other case, the posology was considered inadequate.

Considering that when the indication was considered inadequate, dosage and duration were also considered inadequate, only $93(29.1 \%)$ patients were in use of correct doses and only 101 $(31.6 \%)$ patients presented adequate duration of treatment. Prescription was entirely adequate in only $23.4 \%$ of analyzed prescriptions (TABLE 5). Comparing the group with UGIB suspicion and the one that initiated IV omeprazole for other reasons, prescription was entirely adequate in $31.1 \%$ and $21.6 \%$ of cases, respectively, thus having no statistically significant difference $(P=0.114)$ (TABLE 6).

The median of the number of vials utilized per patient was 6.00 , with variations from 1-74 phials per patient and interquartile amplitude of 2.50-11.00. The median for the number of inadequate vials per patient was 3.00, with variations from $0-60$ inadequate vials per patient and interquartile amplitude of $0.00-7.00$. It was
TABLE 5. Evaluation of prescriptions of patients who used intravenous omeprazole.

\begin{tabular}{|c|c|}
\hline & $\begin{array}{c}\mathrm{n}(\%) \\
\mathrm{n}=320\end{array}$ \\
\hline \multicolumn{2}{|c|}{ Adequate indication } \\
\hline Yes & $133(41.6)$ \\
\hline No & $187(58.4)$ \\
\hline \multicolumn{2}{|c|}{ Adequate dosage* } \\
\hline Yes & $93(29.1)$ \\
\hline No & $227(70.9)$ \\
\hline \multicolumn{2}{|c|}{ Adequate duration* } \\
\hline Yes & $101(31.6)$ \\
\hline No & $219(68.4)$ \\
\hline \multicolumn{2}{|c|}{ Entirely adequate prescription } \\
\hline Yes & $75(23.4)$ \\
\hline No & $245(76.6)$ \\
\hline
\end{tabular}

TABLE 6. Factors associated with adequate and inadequate prescription of intravenous omeprazole.

\begin{tabular}{|c|c|c|c|}
\hline & \multicolumn{2}{|c|}{$\mathrm{n}(\%)$} & \multirow[b]{2}{*}{$P$-value } \\
\hline & $\begin{array}{c}\text { Adequate } \\
\text { prescription }\end{array}$ & $\begin{array}{l}\text { Inadequate } \\
\text { prescription }\end{array}$ & \\
\hline Adequate indications & $\mathrm{n}=74$ & $\mathrm{n}=180$ & \\
\hline $\begin{array}{l}\text { Suspected upper } \\
\text { gastrointestinal bleeding }\end{array}$ & $19(31.1)$ & $42(68.9)$ & $<0.001^{\dagger}$ \\
\hline $\begin{array}{l}\text { Stress ulcer prophylaxis in } \\
\text { patient with high risk of } \\
\text { UGIB unable to receive } \\
\text { orally }\end{array}$ & $44(73.3)^{\mathrm{a}}$ & $16(26.7)$ & \\
\hline $\begin{array}{l}\text { Patient in NPO and valid } \\
\text { indication for PPI usage }\end{array}$ & $11(91.7)^{\mathrm{a}}$ & $1(8.3)$ & \\
\hline Prescribing sector & $\mathrm{n}=75$ & $\mathrm{n}=223$ & \\
\hline $\mathrm{ICU}$ & $44(34.6)^{a}$ & $83(65.4)$ & $0.010^{\dagger}$ \\
\hline General medicine & $18(22.2)$ & $63(77.8)$ & \\
\hline Surgery & $7(12.5)$ & $49(87.5)^{\mathrm{a}}$ & \\
\hline Prescription by ER doctor & $\mathrm{n}=75$ & $\mathrm{n}=245$ & \\
\hline Yes & $15(45.5)^{\mathrm{a}}$ & $18(54.5)$ & $0.002^{\ddagger}$ \\
\hline No & $60(20.9)$ & $227(79.1)^{a}$ & \\
\hline ICU admission & $\mathrm{n}=75$ & $\mathrm{n}=245$ & \\
\hline Yes & $50(31.3)^{\mathrm{a}}$ & $110(68.8)$ & $0.001^{\ddagger}$ \\
\hline No & $25(15.6)$ & $135(34.4)^{a}$ & \\
\hline Evolution to death & $\mathrm{n}=75$ & $\mathrm{n}=245$ & \\
\hline Yes & $31(44.9)^{\mathrm{a}}$ & $38(55.1)$ & $<0.001^{\ddagger}$ \\
\hline No & $44(17.5)$ & $207(82.5)^{a}$ & \\
\hline \multicolumn{4}{|l|}{ Sepsis } \\
\hline Yes & $23(54.5)^{a}$ & $20(45.5)$ & $<0.001^{\ddagger}$ \\
\hline No & $51(18.5)$ & $225(81.5)^{a}$ & \\
\hline \multicolumn{4}{|l|}{ Traumatic brain injury } \\
\hline Yes & $8(66.7)^{a}$ & $4(33.3)$ & $0.001^{\dagger}$ \\
\hline No & $67(21.8)$ & $241(78.2)^{\mathrm{a}}$ & \\
\hline
\end{tabular}

UGIB: upper gastrointestinal bleeding; NPO: nil per os; PPI: proton pump inhibitor; ICU: intensive care unit; ER: emergency room. ${ }^{\dagger}$ Value obtained after applying the Likelihood Ratio test; ${ }^{\ddagger}$ Value obtained after applying the Pearson qui-square test. ${ }^{a}$ Statistically significant value after residual analysis. 
utilized a total of 2853 vials in these 320 patients and, of these, 1696 were considered inadequate. Considering the approximate value of each vial is US\$1.00, it is estimated a cost of US\$1696.00 spent with inadequate use of IV omeprazole prescribed for these patients, and a total of US\$2853.00 with the total of utilized vials evaluated in this study. As it was collected about a third of the number of patient reports of those who used IV omeprazole in six months in the studied hospital, it is estimated a cost of about US $\$ 5088.00$ with the administration of inadequate vials and a cost of US\$8559.00 with the total of vials of IV omeprazole administrated in a period of one semester.

It was observed a statistically significant association between adequate prescription and the following factors: stress ulcer prophylaxis in patients with high risk of UGIB unable to receive medication orally; patient in NPO with valid indication for PPI usage; ICU doctor prescription; evolution to death; sepsis; and traumatic brain injury $(P<0.05)$. Inadequate prescription, however, had a statistically significant association with prescription by the surgical ward and non-evolution to death $(P<0.05)$ (TABLE 6).

\section{DISCUSSION}

This study was conducted in a high complexity hospital evaluating the usage of IV omeprazole during a period of six months. It was verified that the prescription was inadequate in $76.6 \%$ of cases, a higher rate than those observed in studies conducted in other countries ${ }^{(4,11-14)}$.

In the study by Lai et al., in $76.4 \%$ of the cases an unexplained abdominal pain was the reason for initiating the use of IV PPIs and, in these cases, $68.9 \%$ had UGIB suspicion ${ }^{(14)}$. In this present study, the most frequent reason for initiating the use of IV omeprazole was UGIB suspicion, however this occurred in only $19.1 \%$ of cases. Other studies demonstrated that most patients receiving IV PPIs, did it for stress ulcer prophylaxis, data that is compatible with this study, in which it was administered IV omeprazole in 53\% of the patients for prophylaxis of peptic ulcer disease, if we add the patients in high and low risk ${ }^{(4,13)}$.

Former studies observed that most of the doctors responsible for IV PPI prescription were part of the surgical ward ${ }^{(11,14)}$, a data that differs from this present study, in which most of the prescribing doctors were from the ICU (39.7\%) and from the clinical ward $(25.3 \%)$. In this study, it was also observed that half of the patients had an ICU stay. It is possible that patients who were evaluated at the studied institution had a larger admission in this sector in light of being a tertiary hospital, with cases of higher gravity, which could be better evaluated in posterior studies with a larger number of patients.

On a study made in England, IV PPI prescriptions were found to be inadequate in $75.4 \%$ of cases, and most of these patients receiving this medication inadequately had no suspicion of $\mathrm{UGIB}^{(11)}$. In this present study there was a larger percentage of patients in use of IV omeprazole inadequately in the group without UGIB suspicion. There was no statistically significant difference, however, between the group with UGIB suspicion and the group that initiated IV omeprazole for other reasons.

In a Canadian study that evaluated IV PPI prescriptions in cases of UGIB suspicion, it was found that $68 \%$ of the patients underwent an UDE. Of those that underwent endoscopic procedure, $86.2 \%$ had no stigmata for high risk of rebleeding and, of these, $56.9 \%$ remained in use of the medication despite the low risk of rebleeding ${ }^{(18)}$. In regard to the present study, $73.6 \%$ of the patients who underwent UDE did not have high risk of rebleeding, a similar finding to the one observed in the Canadian study, but only $32.3 \%$ of these remained utilizing IV omeprazole 48 hours after the procedure.

In this study, the adequate prescription was associated with stress ulcer prophylaxis in patients with high risk of UGIB unable to receive oral medication; patient in NPO with valid indication for PPI usage; prescription by ICU doctor; prescription by emergency room doctor; ICU admission; evolution to death; sepsis; and traumatic brain injury. The inadequate prescription was associated to surgical ward prescription and non-evolution to death. It is important to highlight that traumatic brain injury and sepsis combined to long stay in ICU were considered adequate indications for stress ulcer prophylaxis in patients with high risk of UGIB unable to receive oral medication. Since all these factors are associated with greater severity and were more prevalent in patients with adequate prescription, we believe they contributed to the association between adequate prescription and evolution to death. The factors associated with adequate and inadequate prescriptions are relevant in facilitating the identification and correction of inadequate practices in health institutions.

This study presented limitations regarding sample. Although the minimum sample was matched, the total number of patient records in use of IV omeprazole in the studied period was not analyzed due to little time available for data collection, and also this being a retrospective study. It is important to point out, however, that there is not sufficient data in literature about how the administration of IV PPIs is carried out in Brazil and Latin America. Thus, this article is still relevant so that greater information regarding the hospital practices in the studied region is obtained.

Knowing that IV PPIs entail a high cost to institutions, a few models were already proposed, suggesting that the administration of these IV medications in every case of suspected UGIB probably is not a cost-effective approach, and also most of the patients treated for UGIB are not hemodynamically unstable ${ }^{(11,19)}$. Although UGIB suspicion still being a formal indication for the use of IV PPIs, a few studies already demonstrated that patients who tolerate oral medication can receive this class of medication this way, which is effective even in cases of bleeding peptic ulcers, entailing a smaller cost that the usage of IV vials ${ }^{(15-17)}$.

Some therapeutic strategies aiming to minimize IV PPIs prescription errors have been shown in literature. In a study conducted by Kaplan et al., it was observed that, initially, only $50 \%$ of the patients receiving IV pantoprazole had adequate indication. A multidisciplinary intervention involving medical education; computerized dosage model; pharmaceutical intervention when a patient without suspected UGIB and with tolerance for oral medication received IV PPI and recommendation of a consult with a gastroenterologist when a continuous infusion of these medications was applied. After this intervention, there was a significant reduction of inadequate prescriptions in the groups with UGIB suspicion $(26 \%)$ and without UGIB suspicion $(41 \%)^{(12)}$.

In the study conducted by Lai et al., every fourth IV PPI prescription received by the pharmaceutical sector was traced against the guidelines from that hospital. PPIs were incorrectly prescribed in $52.8 \%$ of cases and interventions were more effective when made by senior doctors $(100 \%)$, followed by clinical pharmacists $(50 \%)^{(14)}$.

Despite PPIs being considered one of the safest pharmaceuti- 
cal classes, there are potential side effects with chronic use of these medications and gastric suppression in the long term ${ }^{(20)}$. These drugs present few interactions with other drugs. The most notable would be caused by the inhibition of the P450 2C19 cytochrome, especially by omeprazole, leading to a reduction of clopidogrel conversion in its active metabolite, enlarging the risk of cardiovascular diseases in patients who use both medications simultaneously ${ }^{(21)}$. Other drugs which may also be affected by inhibiting the P450 2C19 cytochrome are diazepam, phenytoin and warfarin, while dexlansoprazole and lansoprazole may induce theophylline metabolism by the P450 1A2 cytochrome ${ }^{(22)}$.

The most important side effects related to the usage of these drugs are rebound gastric hypersecretion; hypergastrinemia; hypomagnesemia; reduction of calcium, iron and vitamin B12 absorption; greater risk of bone fracture; enteric infections, with diarrhea by Clostridium difficile the most significant within those; the possibility of spontaneous bacterial peritonitis in cirrhotic patients; community acquired pneumonia; nephrotoxicity and possible augmented risk of dementia and myopathies. There is an inverse relation between gastric acidity and plasmatic levels of gastrin, justifying the hypergastrinemia in chronic users of PPIs. The rise in serum levels of gastrin has the potential to cause cellular hyperplasia in enterochromaffin-like cells, which caused discussions about the possibility of greater development of gastric neoplasia in these patients. There isn't, however, clear evidence that the prolonged use of these drugs predisposes the occurrence of cancers. The appearance of polyps on the gastric fundus region, on the other hand, is common in patients with hypergastrinemia, and they don't seem to have any potential for malignant transformation ${ }^{(23)}$.

In conclusion, this study demonstrated an elevated number of inadequate IV omeprazole prescriptions in the studied hospital, a common problem in many other health institutions in the world, entailing a greater cost associated with the unnecessary administration of vials of this medication. These results prompt the implementation of multidisciplinary intervention strategies and medical education in order to minimize prescription errors, reducing costs and risks involved with IV PPI usage.

\section{Authors' contribution}

Bischoff LM and Faraco LSM: conception and design; analysis and interpretation of the data; drafting of the article; critical revision of the article for important intellectual content. Machado LV, Bialecki AVS and Almeida GM: analysis and interpretation of the data; critical revision of the article for important intellectual content. Becker SCC: conception and design; analysis and interpretation of the data; critical revision of the article for important intellectual content; final approval of the article.

\section{Orcid}

Laura M Bischoff: 0000-0001-7146-6308.

Laura S M Faraco: 0000-0002-3581-3680.

Lucas V Machado: 0000-0001-6809-3918.

Alex V S Bialecki: 0000-0003-2162-4552.

Gabriel M de Almeida: 0000-0002-8031-0943.

Smile C C Becker: 0000-0002-5635-3265.

Bischoff LM, Faraco LSM, Machado LV, Bialecki AVS, Almeida GM, Becker SCC. Uso inapropriado de inibidores de bomba de prótons intravenosos e fatores associados em um hospital de alta complexidade no Brasil. Arq Gastroenterol. 2021;58(1):32-8.

RESUMO - Contexto - Atualmente, o uso intravenoso (IV) dos inibidores de bomba de prótons (IBPs) é indicado em poucas situações, como em casos de hemorragia digestiva alta ou impossibilidade de recebê-los via oral. Há diversos estudos mostrando o uso excessivo desse fármaco, na forma intravenosa, desnecessariamente e acarretando altos custos aos hospitais. Objetivo - Avaliar as indicações, posologias, duração do tratamento e custos das prescrições de omeprazol intravenoso. Métodos - Estudo retrospectivo de 333 pacientes que receberam omeprazol intravenoso entre julho a dezembro de 2018 em um hospital de alta complexidade no Brasil. Resultados - A prescrição de omeprazol intravenoso foi considerada totalmente adequada em apenas $23,4 \%$ das prescrições analisadas. O medicamento foi administrado principalmente em casos de suspeita de hemorragia digestiva alta (HDA) (19,1\%) e profilaxia de úlcera de estresse em paciente com alto risco de HDA impossibilitado de receber via oral (18,7\%). Foi observada associação estatisticamente significativa entre prescrição adequada e profilaxia de úlcera de estresse em paciente com alto risco de HDA impossibilitado de receber medicamento via oral; paciente em nil per os com indicação válida de IBPs; prescrição por médico da UTI; prescrição por médico do pronto atendimento; admissão na UTI; evolução a óbito; sepse; e traumatismo cranioencefálico $(P<0,05)$. Já a prescrição inadequada teve associação estatisticamente significativa com prescrição por setor cirúrgico e a não evolução a óbito $(P<0,05)$. O custo estimado do total de ampolas prescritas inadequadamente foi de US\$1696,00. Conclusão - Houve um elevado número de prescrições de omeprazol intravenoso inadequadas no hospital estudado, acarretando um custo elevado para a instituição.

DESCRITORES - Inibidores da bomba de prótons. Úlcera péptica. Hemorragia gastrointestinal. Prescrição inadequada. Uso off-label. Endoscopia. Sobremedicalização. 


\section{REFERENCES}

1. Shin JM, Sachs G. Pharmacology of proton pump inhibitors. Curr Gastroenterol Rep. 2008;10:528-34.

2. Sachs G, Shin JM, Howden CW. Review article: the clinical pharmacology of proton pump inhibitors. Aliment Pharmacol Ther. 2006;23(s2):2-8.

3. Food and Drug Administration. Highlights of prescribing information: PRILOSEC. [Internet]. [Access 2019 October 10]. Available from: https://www. accessdata.fda.gov/scripts/cder/daf/index.cfm?event=medguide.page

4. Mayet A, Malhani A, Alshaikh M, Alsultan M. Pattern of intravenous proton pump inhibitors use in ICU and Non-ICU setting: A prospective observational study. Saudi J Gastroenterol. 2010;16:275-9.

5. Barletta JF, Bruno JJ, Buckley MS, Cook DJ. Stress Ulcer Prophylaxis. Crit Care Med. 2016;44:1395-405.

6. Anvisa [Internet]. Detalhe do Produto: OMEPRAZOL SÓDICO [Access 2020 June 15]. Available from: https://consultas.anvisa.gov.br/\#/medicamentos/253510164320066/?nomeProduto=OMEPRAZOL $\% 20 \mathrm{~S} \% \mathrm{C3} \% 93 \mathrm{DICO}$

7. Barkun AN. International Consensus Recommendations on the Management of Patients With Nonvariceal Upper Gastrointestinal Bleeding. Ann Intern Med. 2010;152:101-13.

8. Laine L, Jensen DM. Management of Patients With Ulcer Bleeding. Am J Gastroenterol. 2012;107:345-60.

9. Sachar H, Vaidya K, Laine L. Intermittent vs Continuous Proton Pump Inhibitor Therapy for High-Risk Bleeding Ulcers. JAMA Intern Med. 2014;174:1755-62.

10. Lau JYW, Sung JJY, Lee KKC, Yung MY, Wong SK, Wu JC, et al. Effect of Intravenous Omeprazole on Recurrent Bleeding after Endoscopic Treatment of Bleeding Peptic Ulcers. N Engl J Med. 2000 ;343:310-6.

11. Craig DGN, Thimappa R, Anand V, Sebastian S. Inappropriate utilization of intravenous proton pump inhibitors in hospital practice--a prospective study of the extent of the problem and predictive factors. QJM. 2010;103:327-35.

12. Kaplan GG, Bates D, McDonald D, Panaccione R, Romagnuolo J. Inappropriate Use of Intravenous Pantoprazole: Extent of the Problem and Successful Solutions. Clin Gastroenterol Hepatol. 2005;3:1207-14

13. Perwaiz M, Posner G, Hammoudeh F, Schmidt F, Neupane N, Enriquez D, Gulati N. Inappropriate Use of Intravenous PPI for Stress Ulcer Prophylaxis in an Inner City Community Hospital. J Clin Med Res. 2010;215-9.
14. Lai PSM, Wong YY, Low YC, Lau HL, Chin K-F, Mahadeva S. Unexplained abdominal pain as a driver for inappropriate therapeutics: an audit on the use of intravenous proton pump inhibitors. PeerJ. 2014;2:e451.

15. Tsoi KKF, Hirai HW, Sung JJY. Meta-analysis: comparison of oral vs. intravenous proton pump inhibitors in patients with peptic ulcer bleeding. Aliment Pharmacol Ther. 2013;38:721-8

16. Sung JJ, Suen B-Y, Wu JC, Lau JYW, Jessica Y L Ching 1, Vivian W Y Lee, et al. Effects of Intravenous and Oral Esomeprazole in the Prevention of Recurrent Bleeding from Peptic Ulcers after Endoscopic Therapy. Am J Gastroenterol. 2014;109:1005-10. Available from: https://insights.ovid.com/pubmed?p$\mathrm{mid}=24777150$

17. Spiegel BMR, Dulai GS, Lim BS, Mann N, Kanwal F, Gralnek IM. The Cost-Effectiveness and Budget Impact of Intravenous Versus Oral Proton Pump Inhibitors in Peptic Ulcer Hemorrhage. Clin Gastroenterol Hepatol. 2006;4:988-97.e2. Available from: https://linkinghub.elsevier.com/retrieve/pii/S1542356506004885

18. Enns R, Andrews CN, Fishman M, Hahn M, Atkinson K, Kwan P, Levy A. Description of prescribing practices in patients with upper gastrointestinal bleeding receiving intravenous proton pump inhibitors: a multicentre evaluation. Can J Gastroenterol. 2004; 18:567-71

19. Leontiadis GI, Sreedharan A, Dorward S, Barton P, Delaney B, Howden CW, et al. Systematic reviews of the clinical effectiveness and cost-effectiveness of proton pump inhibitors in acute upper gastrointestinal bleeding. Health Technol Assess 2007;11:iii-iv, 1-164. doi: 10.3310/hta11510.

20. Lanas A. We Are Using Too Many PPIs, and We Need to Stop: A European Perspective. Am J Gastroenterol. 2016;111:1085-6. doi:10.1038/ajg.2016.166

21. Ho PM, Maddox TM, Wang L, Fihn SD, Jesse RL, Peterson ED, Rumsfeld JS Risk of adverse outcomes associated with concomitant use of clopidogrel and proton pump inhibitors following acute coronary syndrome. JAMA. 2009;301:937-44. doi:10.1001/jama.2009.261

22. Yang YX, Metz DC. Safety of proton pump inhibitor exposure. Gastroenterology 2010;139:1115-27. doi:10.1053/j.gastro.2010.08.023

23. Savarino E, Marabotto E, Zentilin P, et al. A safety review of proton pump inhibitors to treat acid-related digestive diseases. Expert Opin Drug Saf. 2018;17:785-94. doi:10.1080/14740338.2018.1497155 